\title{
A Novel Dual-Broadband Circularly Polarized Patch Antenna for Precise Satellite Navigation
}

\author{
Fumin Lin $\left(\mathbb{D},{ }^{1}\right.$ Liangxian Zhang $\mathbb{D},{ }^{1}$ Huiping Cai $\mathbb{D}^{1},{ }^{1}$ Mingjian Liu $\mathbb{D},{ }^{1}$ Xiaopeng Li $\mathbb{D}^{2}{ }^{2}$ \\ and Yujie Xiao $\mathbb{D}^{1}$ \\ ${ }^{1}$ School of Physics and Optoelectronic Engineering, Guangdong University of Technology, Guangzhou 510006, China \\ ${ }^{2}$ Hi-Target Surveying Instrument Co. Ltd., Guangzhou 510006, China \\ Correspondence should be addressed to Fumin Lin; linfumin@gdut.edu.cn
}

Received 28 August 2019; Revised 11 November 2019; Accepted 26 November 2019; Published 20 December 2019

Academic Editor: Ding-Bing Lin

Copyright (c) 2019 Fumin Lin et al. This is an open access article distributed under the Creative Commons Attribution License, which permits unrestricted use, distribution, and reproduction in any medium, provided the original work is properly cited.

\begin{abstract}
This paper presents a novel dual-band circularly polarized patch antenna for precise satellite navigation. The radiation elements are composed of the inner cross-shaped patch and the outer annular patch which are printed on the same surface of one substrate. Two patches work in different bands, respectively, and emit dual-band circularly polarized radiation. In order to obtain a more compact antenna to meet the application of precise satellite navigation, we vertically place four metal cylinders under the ends of the cross-shaped patch to form four capacitive loadings to lower the resonant frequency of the inner cross-shaped patch. A capacitive coupling feed structure is used to match the input impedance of a patch antenna and make the antenna compact enough. The simulated and measured results show that the proposed antenna can produce appropriate dual-band circularly polarized radiation patterns for precise satellite navigation. The measured results of the antenna illustrate that maximum RHCP gain of the antenna is $4.72 \mathrm{dBi}$ in the low band and $3.98 \mathrm{dBi}$ in the high band, the $3 \mathrm{~dB}$ gain bandwidth is $70 \mathrm{MHz}$ in the low band and $65 \mathrm{MHz}$ in the high band.
\end{abstract}

\section{Introduction}

Patch antennas are widely used in navigation terminals because of their compact size, low profile, and ease of integration [1]. In the application of the satellite navigation system, the single-frequency receiving terminal cannot obtain accurate position information from the positioning service, so the dual-frequency receiving terminal is expected to be used to improve the positioning accuracy. Currently, the open bands of four running global GNSS consist of L1 $(1575.42 \mathrm{MHz} \pm 5 \mathrm{MHz})$ band and $\mathrm{L} 2(1227.60 \mathrm{MHz} \pm 5 \mathrm{MHz})$ band of GPS, B1 $(1561.10 \mathrm{MHz} \pm 5 \mathrm{MHz})$ band and B2 $(1207.14 \mathrm{MHz} \pm 5 \mathrm{MHz})$ band of Beidou, L1 $(1603.50 \mathrm{MHz}$ $\pm 5 \mathrm{MHz})$ band and $\mathrm{L} 2(1246.50 \mathrm{MHz} \pm 5 \mathrm{MHz})$ band of GLONASS, and E1 $(1575.4 \mathrm{MHz} \pm 5 \mathrm{MHz})$ band and E5b $(1207.14 \mathrm{MHz} \pm 5 \mathrm{MHz})$ band of Galileo. In order to cover all the four systems, the antennas for accurate navigation terminals should have not only dual-frequency circularly polarized characteristics but also two wide bandwidths in both low and high bands (at least $50 \mathrm{MHz}$ in each band).
The challenge of designing a dual-band circularly polarized patch antenna is to achieve both high right-handcircular polarization (RHCP) gain and relatively wide bandwidth in each band. There are many ways to achieve dual-band operation, and slotted techniques are common by introducing an asymmetric slot in the antenna structure to change the current flowing direction and form two distinct resonant frequency bands. Based on this approach, a surfaceopening cross-shaped patch in [2], an edge-opening slotted patch antenna in [3], open-ring slotted antennas in [4,5], an opening S-shaped slotted patch in [6], and an opening asymmetrical arrow-ended cross-slotted antenna in [7] are proposed. But these antennas mentioned above have poor circular polarization performance because the slots break the symmetry of the patch. In [8-11], the antennas realize the dual-band operation by designing two patches which are stacked together. Zuo et al. [12] stacked a layer of parasitic elements over the radiating patches, and the structure introduces two mutually coupled radiating elements. But all these two-patch antennas have much lower RHCP gain. To 
improve the antenna's gain and reduce the back lobe level, a wide dual-band circularly polarized antenna combining slot and microstrip modes with high impedance surface ground plane is reported in [13], but complex manufacturing procedures are required, and it is not suitable for mass production. Two eccentric rings and an arc-shaped conducting strip are introduced to achieve the dual-band CP operation [14], but due to the asymmetry of the structure, the axis ratio (AR) is too large, and the problems of low gain and narrow bandwidth also cannot be resolved.

It has been proved by many studies that the RHCP gain of patch antenna or microstrip antenna can be improved effectively by using the capacitive feed method [15-19]. However, the method of capacitive coupling to generate dual-broadband radiation patterns and increase realized gain at the same time has not been introduced yet.

In this paper, a dual-broadband circularly polarized patch antenna with high RHCP gain and compact structure is proposed. The dual-broadband radiation is achieved by the two coplanar radiating elements, and the inner crossshaped patch loaded with four capacitive loadings at the ends is used to lower the resonant frequency of the high band to meet the demand of precise satellite navigation, while the outer annular patch is used to generate the low frequency. In order to match the input impedance of the ports with phases $0^{\circ}, 90^{\circ}, 180^{\circ}$, and $270^{\circ}$ of the patch antenna and achieve the wide bandwidth, a novel capacitive coupling feed method is introduced. Four metal discs are placed under proposed patches to form capacitive coupling structure to feed the outer annular radiating element and the inner cross-shaped radiating element simultaneously. With this new technology mentioned above, the proposed patch antenna has excellent performances such as dual-broadband radiation patterns, high gain, and low back lobe radiation.

\section{Design and Analysis}

2.1. Radiating Element. The proposed antenna consists of a ground plane, two-patch antenna elements, the feed structure, and two TP-2 substrates with a relative dielectric constant 4.5 and a loss angle tangent 0.002 , as shown in Figure 1, and the dimension parameters are given in Table 1. The parameter $\theta$ is $45^{\circ}$. The radiating elements are composed of an annular patch and a cross-shaped patch inside the annular patch, which are printed together on the top plane of the upper substrate. Each patch operates on its own dominant resonant frequency, and the annular patch is used as the radiating element of GPS-L2 band $(1.225 \mathrm{GHz})$, while the cross-shaped patch is considered as the radiating element of GPS-L1 band $(1.582 \mathrm{GHz})$. The parameter $c$ is the gap length between the cross-shaped patch and the metal cylinder. In order to understand the working principle of the capacitive loading and study the relationship between the resonant frequency of the cross-shaped patch and parameter $c, c$ is not equal to the height of the substrate $1\left(h_{2}\right)$ at first. But fortunately, when $c$ is equal to $h_{2}$, the high resonant frequency meets the need of the high band.

Actually, the resonant frequency of the cross-shaped patch inside the annular patch is much higher than the L1 frequency without the innovative feed structure mentioned in this paper. Therefore, it is necessary to introduce a new feed structure and a new loading technology. The metallic cross patch, metal cylinder, and the dielectric 1 between them can be considered as a capacitive loading to miniaturize the size of the cross patch. And with this introduction, the cross patch can be compact enough to be set inside the annular patch. Furthermore, it is necessary to use this capacitive loading to reduce the inductive part of the cross patch antenna impedance. Meanwhile, a specific feed network, which is used to generate the specific signals to feed the antenna to realize the circular polarization radiation, can also be considered as a broadband impedance converter that enables us to get a good impedance matching in the working band. The cross-shaped patch can be considered as four sections of one-quarter wavelength transmission lines, and the cross-shaped patch is connected to the ground plane through a shorting probe in its center in order to create a short-circuit condition and maintain the stability of the phase center of the antenna. According to the theory of the short-circuited coaxial cavity, four copper cylinders are embedded symmetrically in the substrates under the ends of the cross-shaped patch to lower its resonant frequency. The bottom planes of the cylinders are connected to the ground plane, and there are four substrate gaps between the top planes of the cylinders and the cross-shaped patch, and this structure can be considered as a capacitive coupling mechanism.

For one section of transmission line with terminal shorted, the resonance condition is that admittance equals zero. However, when the capacitive loading is introduced, with the change of the capacitance value, the length of the transmission line to achieve the resonance is

$$
l_{0}=\frac{\lambda_{0}}{2 \pi} \tan ^{-1} \frac{1}{\omega C Z}<\frac{\lambda}{4}
$$

where the parameter $C$ is the coupling capacitance. The resonance frequency is given by (1), and it can be shown in Figure 2. Obviously, the resonant frequency of the crossshaped patch is not only determined by the length and width of the patch but also determined by the coupling capacitance. The resonant frequency can be lowered to the GPS-L1 band by increasing the coupling capacitance, and it can be increased by decreasing the length of gaps. Figure 3 gives the return loss of the antenna with the change of gap length $(c)$. It can illustrate that the resonant frequency of the crossshaped patch decreases with the decrease of the gap length. With this innovative method, the radiation patches operating in two frequency bands can be laid on the same plane of the same substrate.

2.2. Feed Mechanism. As the traditional circularly polarized antennas, two coaxial ports are directly connected to the radiation patch and used to feed two signals with equal amplitude but $90^{\circ}$ phase difference to the patches, to excite two orthogonal resonant modes. However, the impedance bandwidth obtained by this method is narrow. Besides, the input impedance of the annular patch is far beyond $50 \mathrm{ohm}$ 


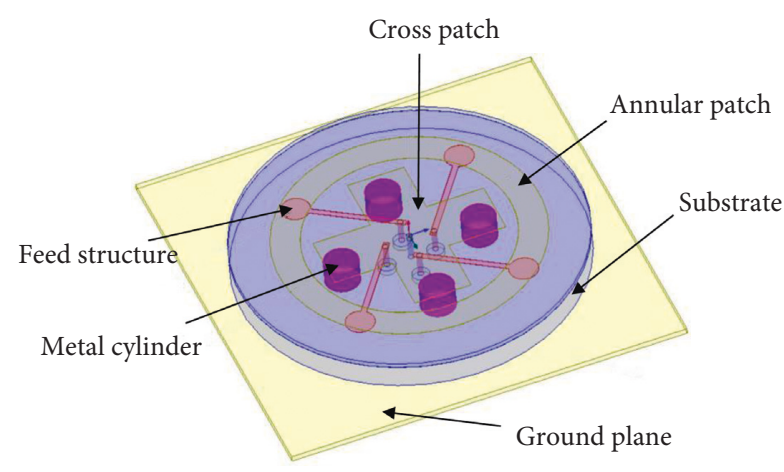

(a)

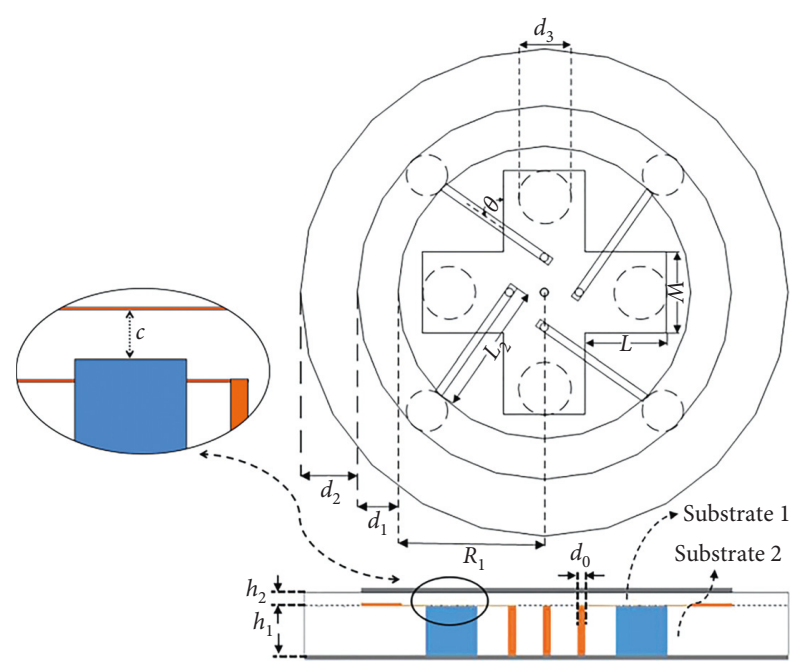

(b)

Figure 1: Geometry of the proposed antenna. (a) Three-dimensional view. (b) Side view and top view.

TABLE 1: The structural parameters of the proposed antenna $(\mathrm{mm})$.

\begin{tabular}{lccccccccc}
\hline$L$ & $W$ & $L_{2}$ & $R_{1}$ & $d_{1}$ & $d_{2}$ & $d_{3}$ & $d_{0}$ & $h_{1}$ & $h_{2}$ \\
\hline 12 & 10 & 19 & 16.4 & 6 & 7.6 & 7.6 & 1 & 4.2 & 0.8 \\
\hline
\end{tabular}

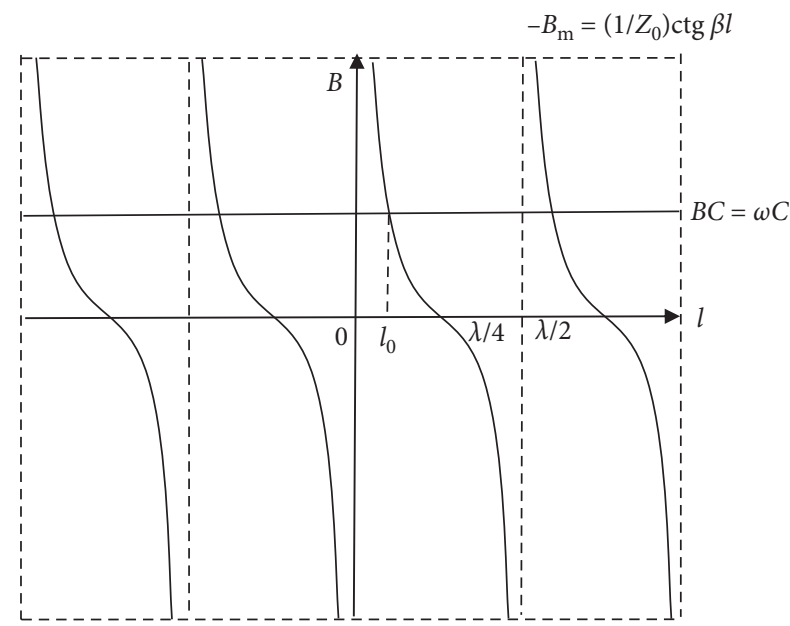

Figure 2: Solution to (1) for the resonant frequencies of the coaxial cavity.

because of the coupling effect of the inner cross-shaped patch.

It is difficult to achieve the input impedance matching when we connect the $50 \mathrm{ohm}$ port to the radiating patch directly. In order to achieve the impedance matching and improve the impedance bandwidth, a four-port capacitive coupling feed mechanism is proposed in this paper. There are four circular discs to be placed under the annular patch and laid on the top plane of the lower substrate, and each disc is connected to the coaxial port by the microstrip transmission line. Therefore, the gap between the discs and the annular patch and the gap between the microstrip lines and the cross-shaped patch have been considered as the

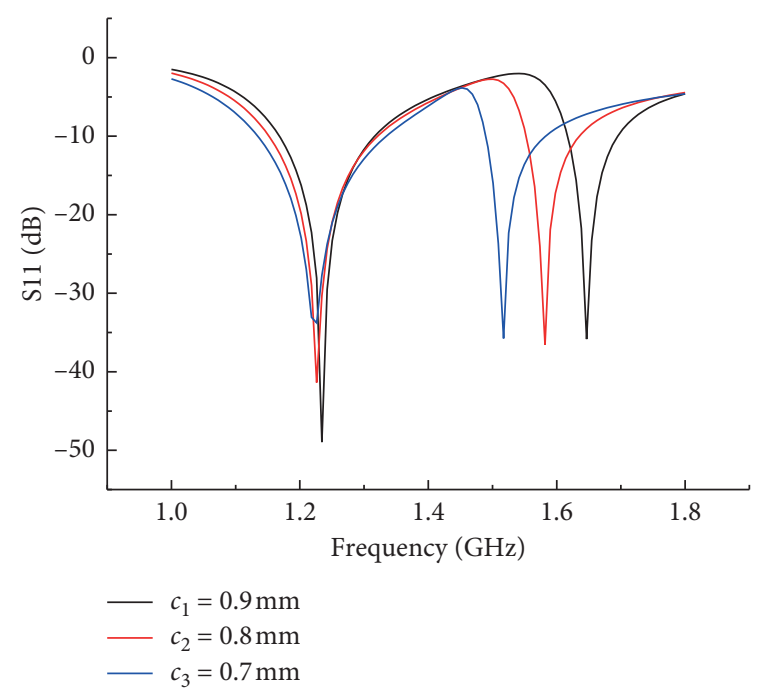

FIGURE 3: Return loss of the antenna with the change of gap length (c).

capacitive coupling feed mechanism. As many researchers know, it is helpful to realize a wide impedance bandwidth by introducing the capacitive-coupled loading. The signal phases of the four ports are $0^{\circ}, 90^{\circ}, 180^{\circ}$, and $270^{\circ}$, and the pure circular polarized radiation could be obtained by optimizing the impedance matching. Compared with two-port feed method, the capacitive coupling feed method proposed in this paper enables us to obtain a better impedance matching and a wider impedance bandwidth, as shown in Figures 3 and 4. By using innovative capacitive coupling structure and the specific four feed ports to introduce multimode resonance of each feed port, the impedance bandwidth of the L2 band (center frequency of $1.225 \mathrm{GHz}$ ) is $100 \mathrm{MHz}$ and the impedance bandwidth of L1 band (center frequency of $1.582 \mathrm{GHz}$ ) is relatively narrowed, but there is still more than $80 \mathrm{MHz}$ enough to cover the L1 band of the four satellite navigation systems. It can be seen that the frequency range of reflection parameter S11 less than $-10 \mathrm{~dB}$ 


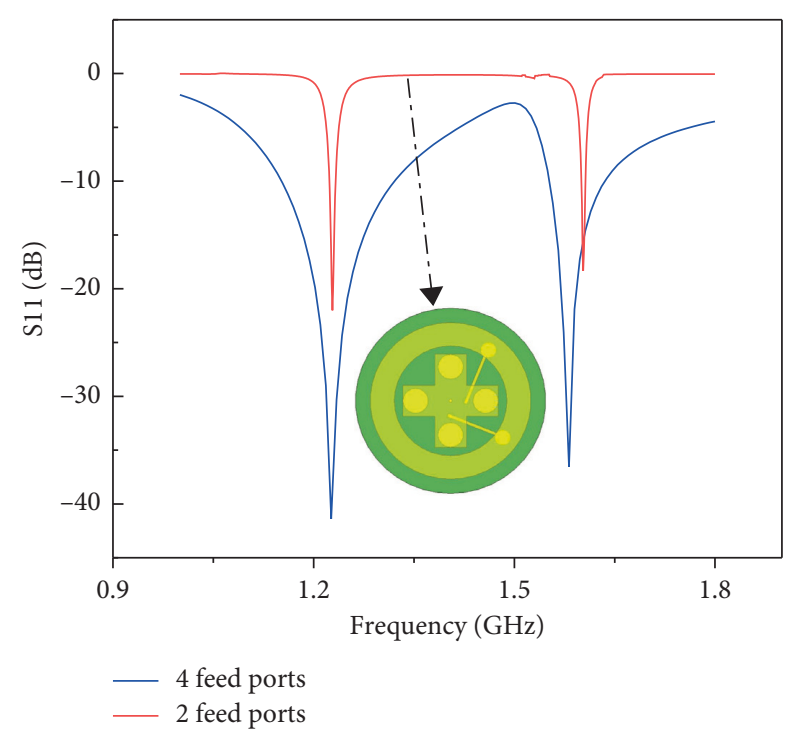

FIGURE 4: Simulated S11 of two kinds of feed.

in $\mathrm{L} 2$ band is from $1.174 \mathrm{GHz}$ to $1.284 \mathrm{GHz}$ and the impedance bandwidth is $110 \mathrm{MHz}$. The frequency range of the reflection parameter S11 less than $10 \mathrm{~dB}$ in the $\mathrm{L} 1$ band is from $1.550 \mathrm{GHz}$ to $1.634 \mathrm{GHz}$, and the impedance bandwidth is $84 \mathrm{MHz}$.

Because of the capacitance between the metal feed structure and the radiation patch, the resonant frequency will be lowered to some extent. The impedance matching is determined by the capacitance of the feed structure, while the wide bandwidth can be achieved by optimizing the structural parameters of the coupling structure and the radiating patches. Moreover, the gap determines the coupling capacitance, and its thickness is equal to the thickness of the upper substrate which has an important effect on the capacitive coupling feed mechanism, so it is expected to be carefully optimized.

Figure 5 gives the intensity of the electric field pattern on the annular patch and the cross-shaped patch. In a time period, we can see that the electric field rotates in the righthand form as time changes, which means that the proposed antenna has the good performance of right-handed circular polarization radiation. For the L2 band, the electric field shown in Figure 5(a) is mainly generated in the gaps between the discs and the annular patch because of the capacitor between them. Similarly, for the L1 band, the electric field shown in Figure 5(b) is mainly generated in gaps between the copper cylinders and the cross-shaped patch. It can be seen that the cross-shaped patch radiates in the high band while the annular patch radiates in the low band. If we do not use the novel feed structure named as capacitive loading, the resonant frequency of the cross-shaped patch is not low enough to enable us to put this patch inside the annular patch. Combined with the feed network, the proposed structure has been fabricated.

\section{Results and Discussion}

Figure 6 gives the photographs of the antenna. The antenna is supported by a square substrate which is used to print the feed network, and it is considered as the antenna ground plane. The back circuit of the antenna is the feed network, and the input signal, after using three $90^{\circ}$ mixers, is divided into four signals with equal amplitude and different phases $\left(0^{\circ}, 90^{\circ}, 180^{\circ}\right.$, and $\left.270^{\circ}\right)$ to feed the radiation antenna. Just as shown in Figure 6, based on the FR4 substrate, the specific feed network of the antenna can be printed on the bottom side of the structure. It is obvious that CP radiation can be achieved by the proposed wideband phase-shifting feed network. Three $90^{\circ}$ phase shifters have been used to generate the specific signal. The center of the antenna is fixed with a shorted pin to shield the electric field from interference so that the electric field in the center is maintained at zero. There is no doubt that the passive and active return loss should be shown together. Feed network can also be considered as an impedance converter, which is beneficial to increase bandwidth, so the bandwidth with feed network could be larger is predictable. Figure 7 shows the simulated return loss of the proposed antenna and the feed network, which illustrates that the antenna and the feed network have a low reflection coefficient, respectively. With the specific feed network, the bandwidth of return loss may be larger. The curve of "antenna" means the simulated return loss of one port of 4 ports of feeding antenna, and we just show one of the four input feeding ports because of the same performance of each port. To generate the specific signals to feed the antenna, a feeding network with one input port and four output ports of equal amplitude and phase difference of 90 degrees $\left(0^{\circ}, 90^{\circ}, 180^{\circ}\right.$, and $\left.270^{\circ}\right)$ is introduced in this paper. The curve of "feed network" means the return loss of the single input port of the feeding network.

In order to realize the circular polarization, a specific feed network is proposed. And we can combine the antenna with the feed network to get the fabricated antenna system which only has one input port. As shown in Figure 8, the measured return loss and standing wave ratio (SWR) of the antenna system mentioned above occur. From what has mentioned above, when we combine the antenna with feed network, the bandwidth of the impedance will be increased, just as shown in Figure 5. The measured return loss is lower than $-10 \mathrm{~dB}$ from $1.0 \mathrm{GHz}$ to $1.8 \mathrm{GHz}$, while the measured SWR is lower than $2 \mathrm{~dB}$.

Figure 9 shows the measured maximum RHCP gain versus frequency of the antenna. It illustrates that the maximum gain of the $\mathrm{L} 2$ band is $4.72 \mathrm{dBi}$ at $1.28 \mathrm{GHz}$ and the $3 \mathrm{~dB}$ gain bandwidth is $70 \mathrm{MHz}$, while the maximum gain of the $\mathrm{L} 1$ band is $3.98 \mathrm{dBi}$ at $1.6 \mathrm{GHz}$ and the $3 \mathrm{~dB}$ gain bandwidth is $65 \mathrm{MHz}$. Obviously, each gain bandwidth of two bands meets the requirements of the four navigation system transceiver bands. Obviously, the difference in the L2 band can be seen, but it can be explained by the fabrication accuracy of the annular patch and the dimensions of the feed structure which influence the resonant frequency of the annular patch greatly.

Figure 10 shows the measured radiation patterns of the L1 band and L2 band of the proposed antenna. The measured results show that the maximum radiation RHCP gain of the antenna is $4.13 \mathrm{dBi}$ at theta $=4^{\circ}$ for the $\mathrm{L} 2$ band and the maximum gain of the $\mathrm{L} 1$ band is $3.6 \mathrm{dBi}$ at theta $=3.5^{\circ}$, and 
$t=0$

$E$ field $[\mathrm{V} / \mathrm{m}]$

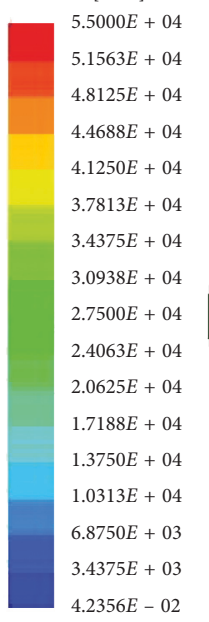

$t=T / 2$

$E$ field $[\mathrm{V} / \mathrm{m}]$

$5.5000 E+04$
$5.1563 E+04$
$4.8125 E+04$
$4.4688 E+04$
$4.1250 E+04$
$3.7813 E+04$
$3.4375 E+04$
$3.0938 E+04$
$2.7500 E+04$
$2.4063 E+04$
$2.0625 E+04$
$1.7188 E+04$
$1.3750 E+04$
$1.0313 E+04$
$6.8750 E+03$
$3.4375 E+03$
$4.2356 E-02$

$t=T / 4$

$E$ field $[\mathrm{V} / \mathrm{m}]$
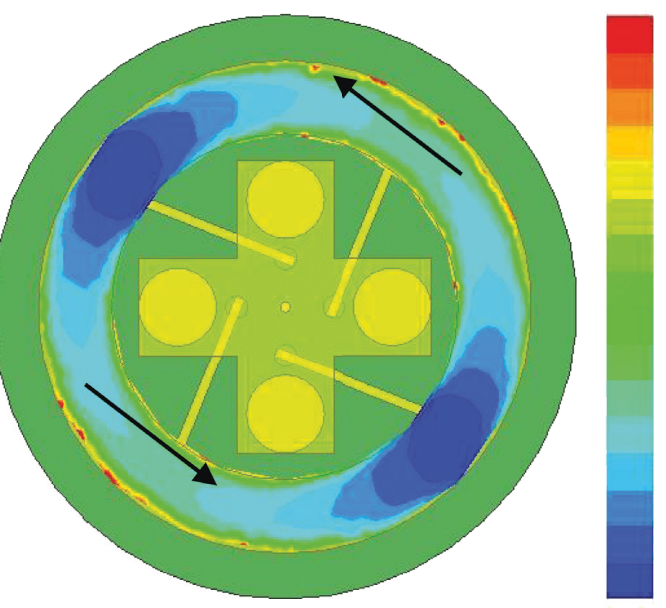

$5.5000 E+04$

$5.1563 E+04$

$4.8125 E+04$

$4.4688 E+04$

$4.1250 E+04$

$3.7813 E+04$

$3.4375 E+04$

$3.0938 E+04$

$2.7500 E+04$

$2.4063 E+04$

$2.0625 E+04$

$1.7188 E+04$

$1.3750 E+04$

$1.0313 E+04$

$6.8750 E+03$

$3.4375 E+03$

$4.2356 E-02$

$t=3 T / 4$

$E$ field $[\mathrm{V} / \mathrm{m}]$
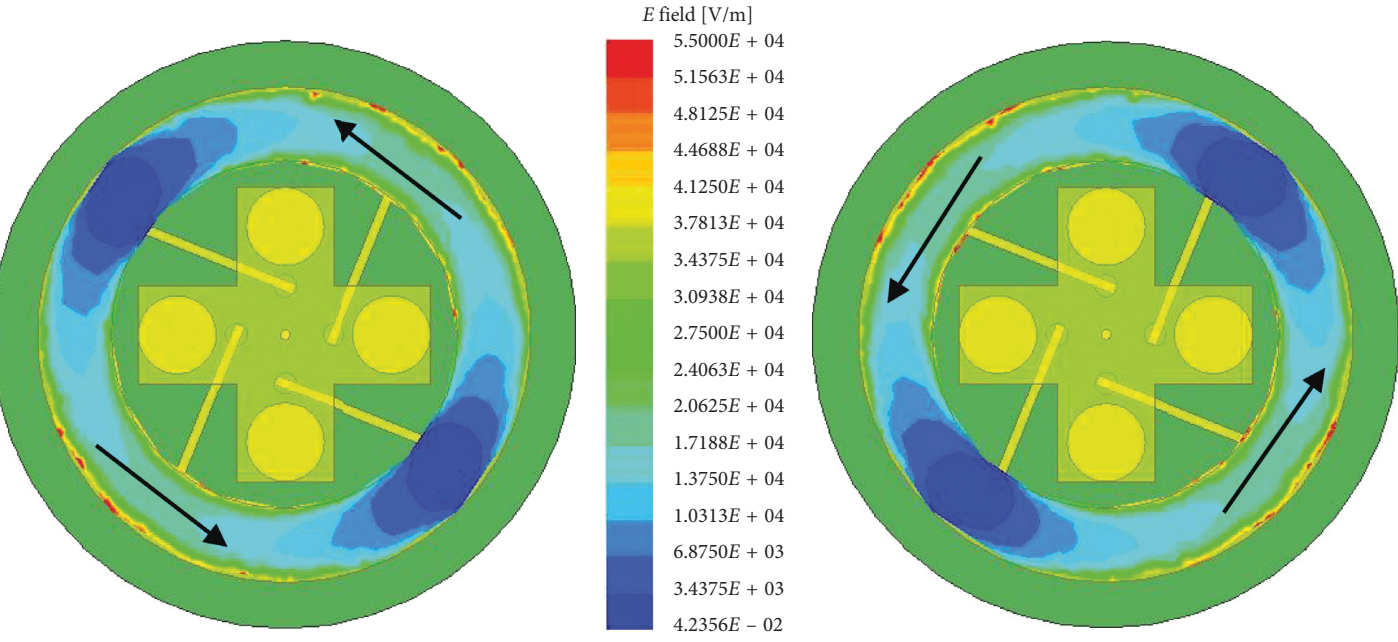

(a)

Figure 5: Continued. 
$t=0$

$E$ field $[\mathrm{V} / \mathrm{m}]$

$1.6874 E+005$
$1.5749 E+005$

$1.4624 E+005$

$1.3499 E+005$

$1.2374 E+005$

$1.1249 E+005$

$1.0124 E+005$

$8.9993 E+004$

$7.8744 E+004$

$6.7495 E+004$

$5.6245 E+004$

$4.4996 E+004$

$3.3747 E+004$

$2.2498 E+004$

$1.1249 E+004$

$9.7594 E-002$

$t=T / 2$

$E$ field $[\mathrm{V} / \mathrm{m}]$

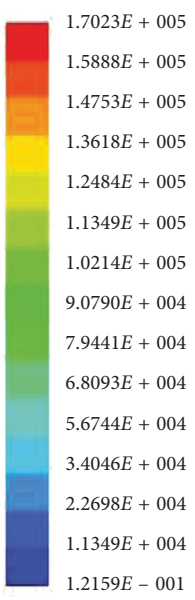

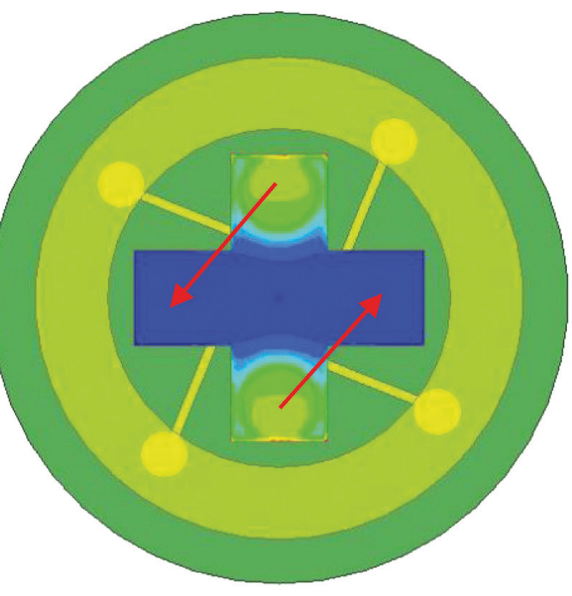

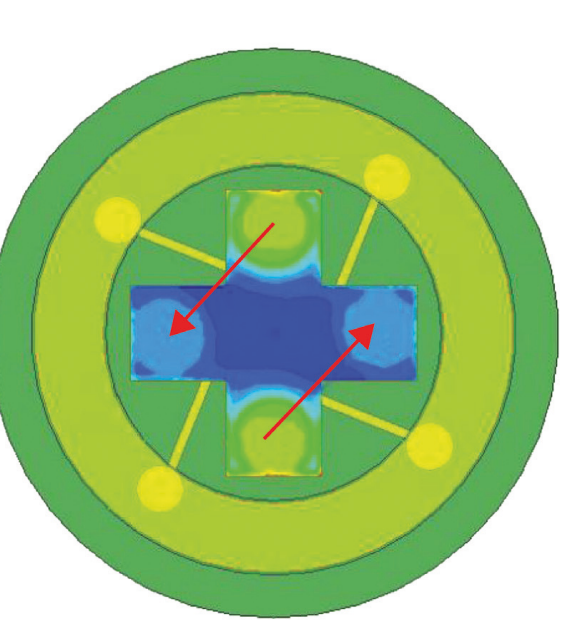

$t=T / 4$

$E$ field $[\mathrm{V} / \mathrm{m}]$

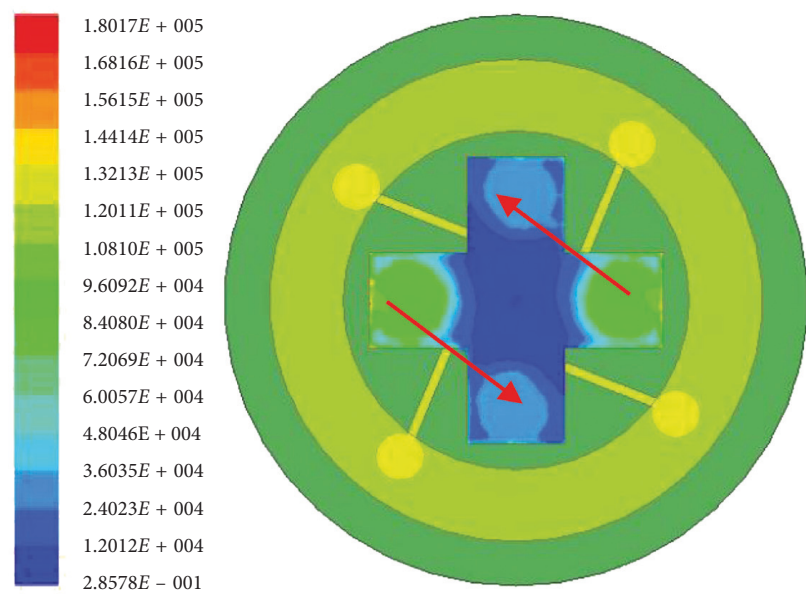

$2.8578 E-001$

$t=3 T / 4$

$E$ field $[\mathrm{V} / \mathrm{m}]$
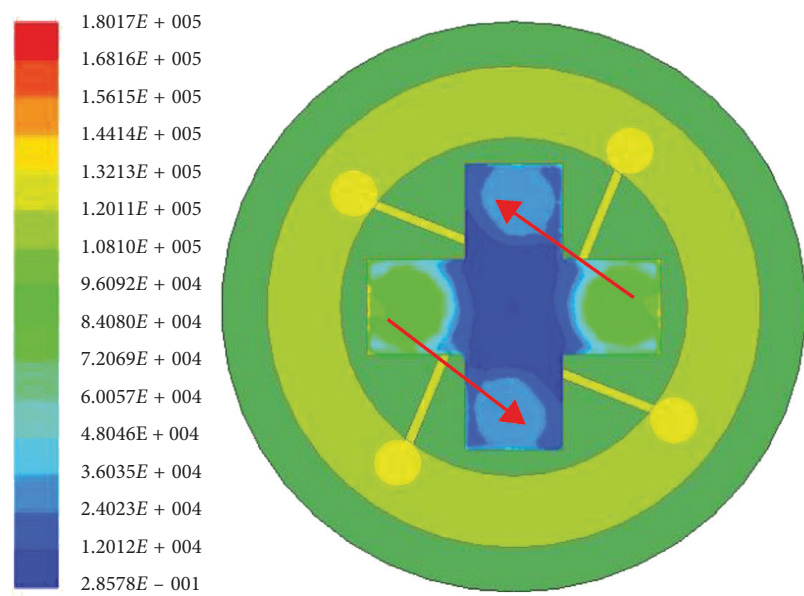

(b)

Figure 5: Electric field distributions of the antenna at (a) $1.225 \mathrm{GHz}$ (L2) and (b) $1.582 \mathrm{GHz}$ (L1).

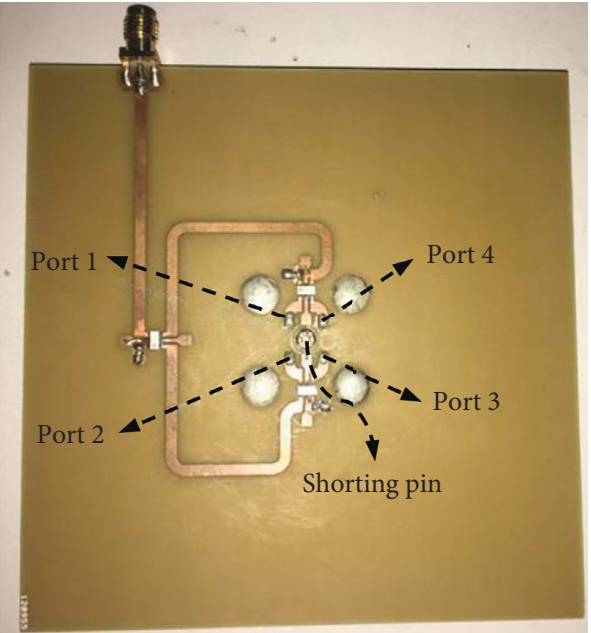

(a)

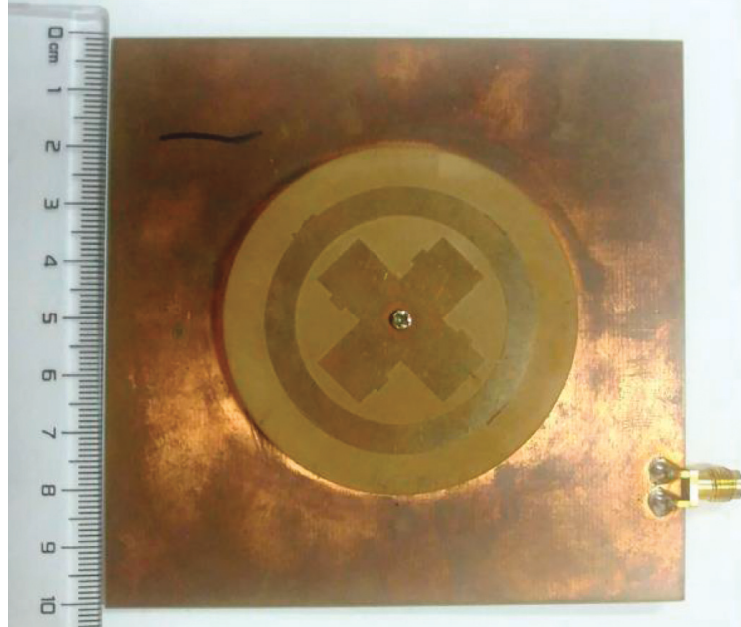

(b)

Figure 6: Photograph of the fabricated prototype antenna. 


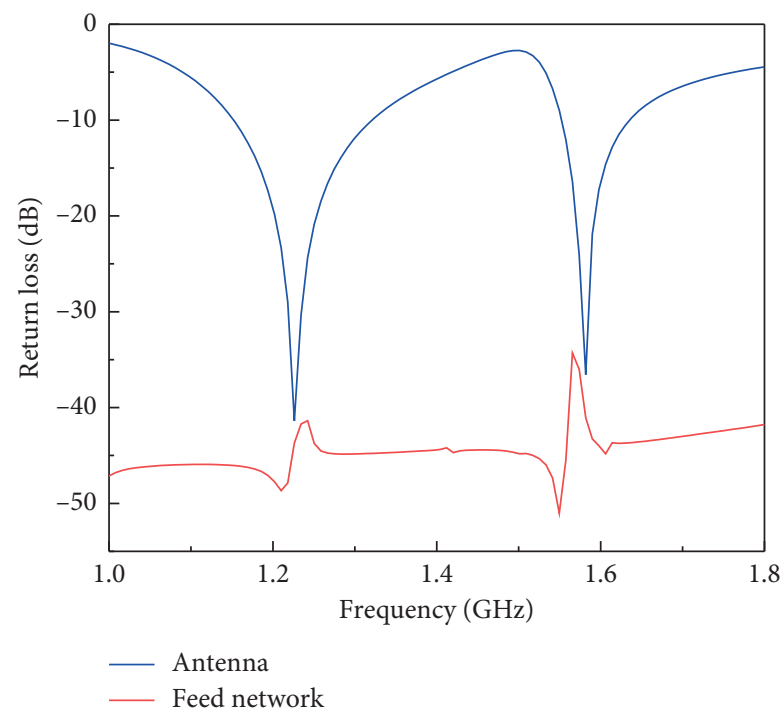

Figure 7: The simulated return loss of the antenna and the feed network.

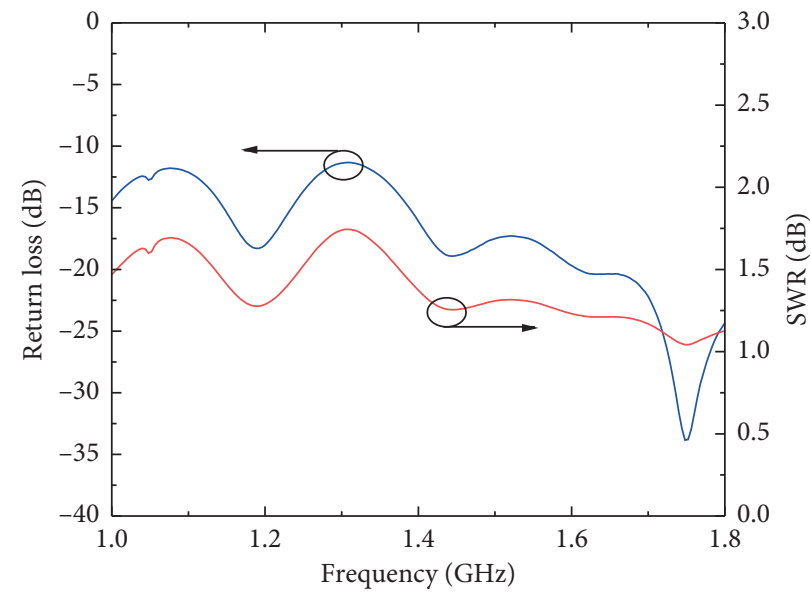

- Measured return loss

— Measured SWR

FIGURE 8: The measured return loss and SWR.

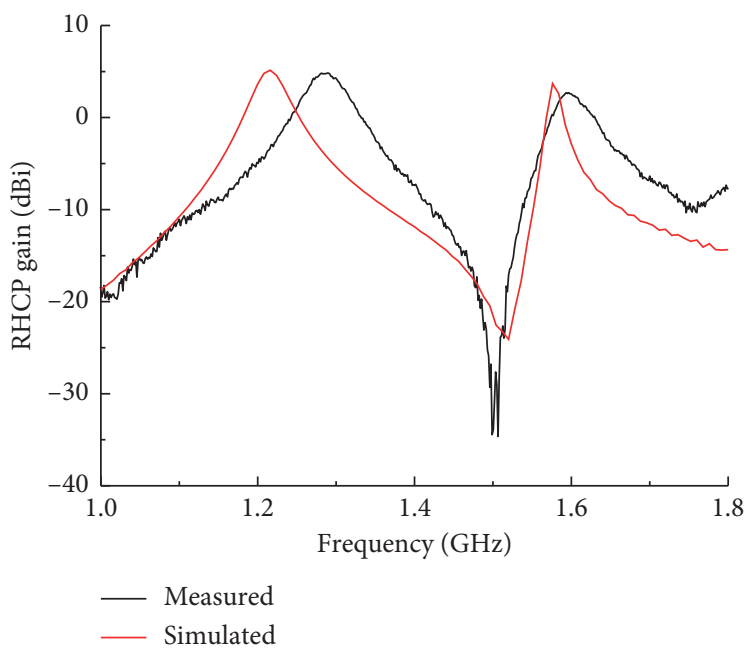

FIGURE 9: RHCP gain of the proposed antenna. 


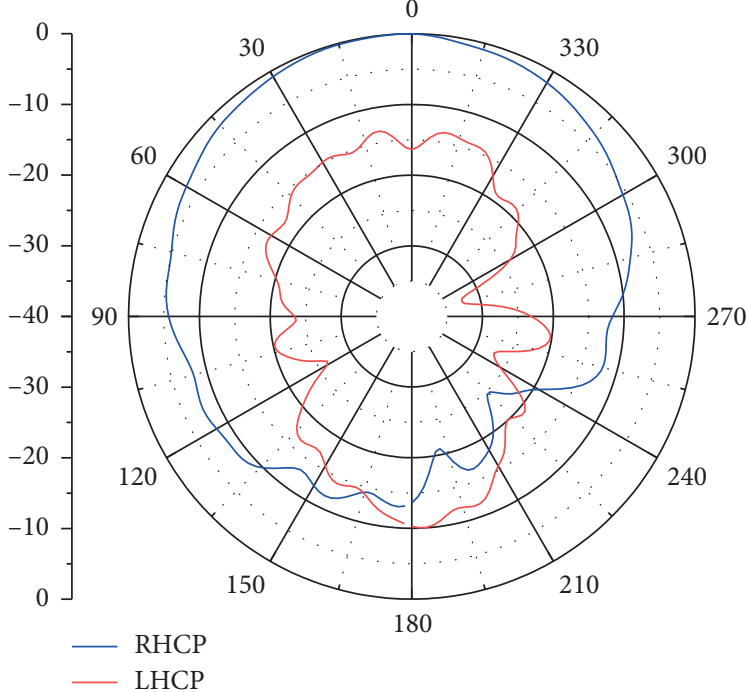

(a)

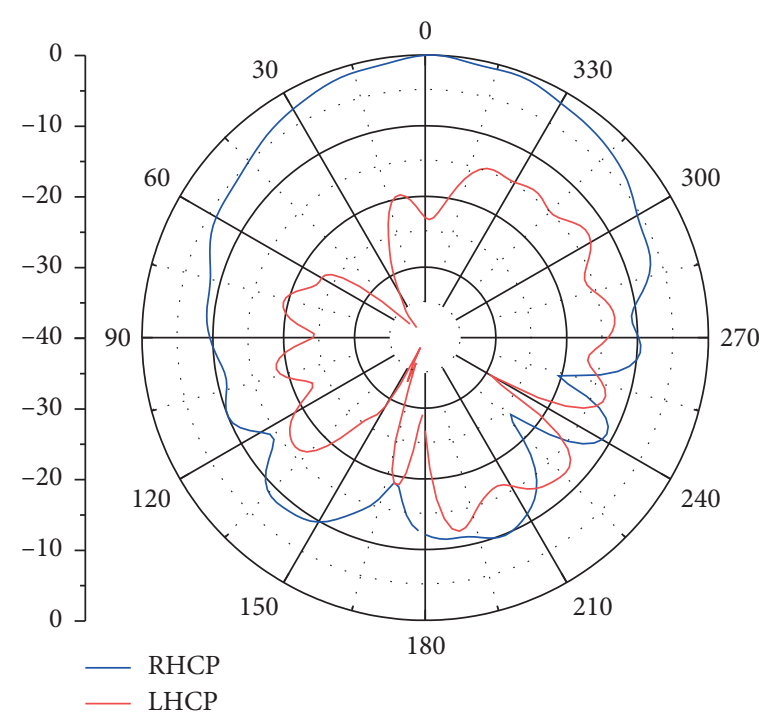

(b)

FIGURE 10: Measured radiation patterns of the proposed antenna at (a) $1.225 \mathrm{GHz}$ and (b) $1.582 \mathrm{GHz}$.

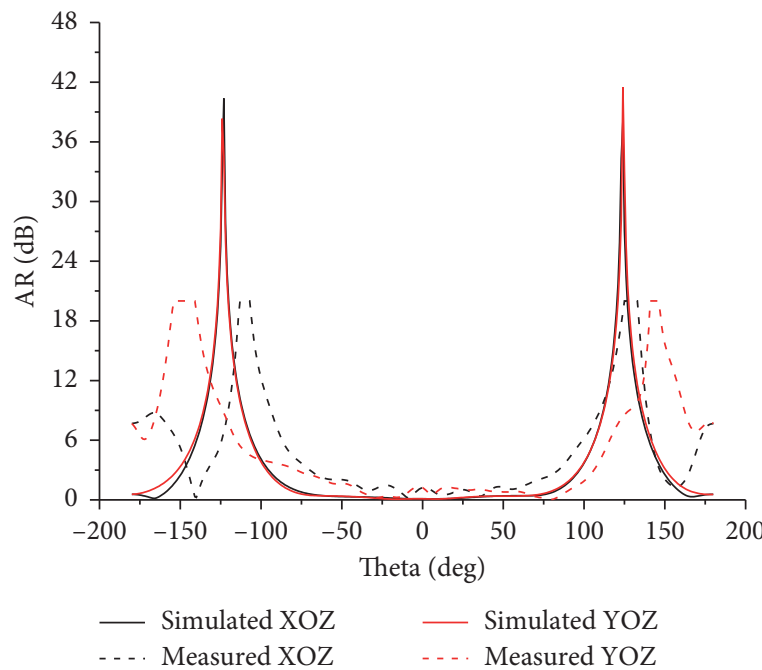

(a)

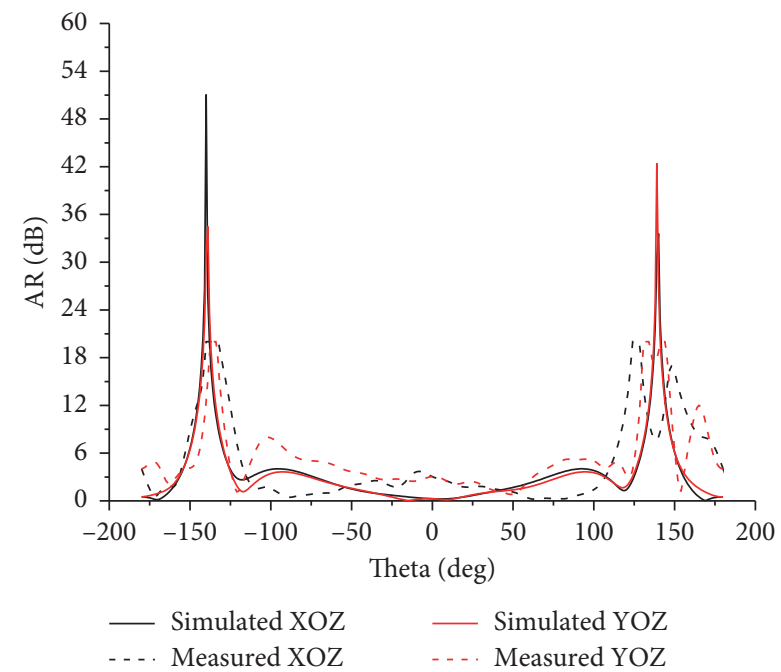

(b)

FIGURE 11: Axial ratio of the proposed antenna at (a) $1.225 \mathrm{GHz}$ and (b) $1.582 \mathrm{GHz}$.

the proposed antenna has a good radiation pattern. It is obvious that a higher RHCP gain and a wider half-power lobe bandwidth are obtained. The antenna radiates a unidirectional circular polarized wave.

The simulated and measured axis ratios at $1.225 \mathrm{GHz}$ and $1.582 \mathrm{GHz}$ are shown in Figure 11. At $1.225 \mathrm{GHz}$, the $3 \mathrm{~dB}$ $\mathrm{AR}$ widths of the proposed antenna in the $\mathrm{XOZ}$ plane and YOZ plane are $134^{\circ}$ and $160^{\circ}$, respectively. At $1.582 \mathrm{GHz}$, the $3 \mathrm{~dB}$ AR widths of the proposed antenna in the XOZ plane and YOZ plane are $150^{\circ}$ and $156^{\circ}$, respectively. The measured result shows that the axis ratios of the antenna at both $\mathrm{XOZ}$ plane and YOZ plane have a deviation from the simulated data, which is caused by the antenna testing process and some other factors. The overall axial ratio performance indicates that the proposed antenna has a wide axial ratio bandwidth and good radiation performances.

The comparisons between the simulated and measured results can be seen in Table 2 . The simulated resonant frequency of the antenna without specific feed network meets the need of the L1 band and L 2 band. Fabricated with the feed network, the $-10 \mathrm{~dB}$ impedance bandwidth of the proposed antenna system is $800 \mathrm{MHz}$, from $1.0 \mathrm{GHz}$ to $1.8 \mathrm{GHz}$. But we can see that the peak measured gains of two bands are $4.72 \mathrm{dBi}$ at $1.28 \mathrm{GHz}$ and $3.98 \mathrm{dBi}$ at $1.6 \mathrm{dBi}$, respectively, while the peak simulated gains are $4.58 \mathrm{dBi}$ at $1.225 \mathrm{GHz}$ and $3.68 \mathrm{dBi}$ at $1.582 \mathrm{GHz}$, respectively. This problem may be caused by the fabrication accuracy of the structure size, and it can be seen from the results that it just 
TABLE 2: Comparisons between the simulated and measured results.

\begin{tabular}{lccc}
\hline & S11 $(-10 \mathrm{~dB})$ & Peak RHCP gain & Gain bandwidth (3 dB) \\
\hline \multirow{2}{*}{ Simulated } & $1.174 \mathrm{GHz}-1.284 \mathrm{GHz}$ & $4.58 \mathrm{dBi}$ at $1.225 \mathrm{GHz}$ & $30 \mathrm{MHz}$ at L1 band \\
& $1.550 \mathrm{GHz}-1.634 \mathrm{GHz}$ (without feed network) & $3.68 \mathrm{dBi}$ at $1.582 \mathrm{GHz}$ & $60 \mathrm{MHz}$ at L2 band \\
\hline \multirow{2}{*}{ Measured } & \multirow{2}{*}{$1.0 \mathrm{GHz}-1.8 \mathrm{GHz}$ (with feed network) } & $4.72 \mathrm{dBi}$ at $1.28 \mathrm{GHz}$ & $65 \mathrm{MHz}$ at L1 band \\
& & $3.98 \mathrm{dBi}$ at $1.60 \mathrm{GHz}$ & $70 \mathrm{MHz}$ at L2 band \\
\hline
\end{tabular}

TABLE 3: Comparisons between our design and previous antennas.

\begin{tabular}{|c|c|c|c|c|}
\hline Antenna & Reference [20] & Reference [21] & Reference [22] & This work \\
\hline$\varepsilon_{\mathrm{r}}$ & 3 & $\begin{array}{l}\varepsilon_{\mathrm{r} 1}=9.8 \\
\varepsilon_{\mathrm{r} 2}=45\end{array}$ & 9.8 & 4.5 \\
\hline $3 \mathrm{~dB}$ gain bandwidth & $\begin{array}{l}45 \mathrm{MHz} \text { at } \mathrm{L} 1 \\
40 \mathrm{MHz} \text { at } \mathrm{L} 2\end{array}$ & $\begin{array}{l}50 \mathrm{MHz} \text { at } \mathrm{L} 1 \\
45 \mathrm{MHz} \text { at } \mathrm{L} 2\end{array}$ & $\begin{array}{l}35 \mathrm{MHz} \text { at } \mathrm{L} 1 \\
26 \mathrm{MHz} \text { at } \mathrm{L} 2\end{array}$ & $\begin{array}{l}65 \mathrm{MHz} \text { at } \mathrm{L} 1 \\
70 \mathrm{MHz} \text { at } \mathrm{L} 2\end{array}$ \\
\hline Peak polarization gain & $\begin{array}{l}4.2 \mathrm{dBi} \text { at } \mathrm{L} 1 \\
-1 \mathrm{dBi} \text { at } \mathrm{L} 2\end{array}$ & $\begin{array}{l}3.5 \mathrm{dBi} \text { at } \mathrm{L} 1 \\
3.2 \mathrm{dBi} \text { at } \mathrm{L} 2\end{array}$ & $\begin{array}{l}3.1 \mathrm{dBi} \text { at } \mathrm{L} 1 \\
4.9 \mathrm{dBi} \text { at } \mathrm{L} 2\end{array}$ & $\begin{array}{l}3.98 \mathrm{dBi} \text { at } \mathrm{L} 1 \\
4.72 \mathrm{dBi} \text { at } \mathrm{L} 2\end{array}$ \\
\hline Impedance bandwidth $(-10 \mathrm{~dB})$ & $1.15 \mathrm{GHz}-1.60 \mathrm{GHz}$ & $1.1 \mathrm{GHz}-1.7 \mathrm{GHz}$ & $\begin{array}{l}14 \mathrm{MHz} \text { at } \mathrm{L} 1 \\
16 \mathrm{MHz} \text { at } \mathrm{L} 2\end{array}$ & $1.0 \mathrm{GHz}-1.8 \mathrm{GHz}$ \\
\hline
\end{tabular}

has little effect on the frequency. We can adjust the resonant frequency by optimizing the size of the patch antenna. In terms of the gain bandwidth, the measured $3 \mathrm{~dB}$ gain bandwidth performs better. In order to compare our work with other antennas, Table 3 provides the detailed performances of them. It is obvious that the proposed antenna has the best performances in impedance bandwidth, $3 \mathrm{~dB}$ gain bandwidth, and RHCP gain. Furthermore, compared with other antennas, the proposed antenna may be easier to be processed.

\section{Conclusion}

The dual-broadband circularly polarized antenna proposed in this paper realizes a coplanar miniaturized design by introducing capacitive loading technology and innovative feed structure. Moreover, in order to solve the problem of narrow radiation bandwidth of the microstrip antenna, a new type of four-port capacitive coupling feed method is proposed, which can greatly widen the radiation bandwidth on the premise of sacrificing the RHCP gain in a certain extent. The proposed antenna will be greatly widely used in the miniaturized precise navigation terminal. In addition, in order to meet the requirements of the L1 frequency band of the four major navigation systems, four metal cylinders are placed symmetrically under the cross-shaped patch to form coupling capacitors so that the resonant frequency can be eventually reduced in a certain extent by appropriately changing the capacitance value.

The measured gain shows that the maximum gain of the antenna is about $4 \mathrm{dBi}$ in both frequency bands, and the $3 \mathrm{~dB}$ gain bandwidth is more than $60 \mathrm{MHz}$. The measured axial ratio shows that the antenna has good circular polarization performance. The measured results are in good agreement with the simulation results and meet the requirements of the four navigation systems in the civil frequency band. Therefore, the proposed dual-band circularly polarized antenna has its distinct application value and prospects.

\section{Data Availability}

The data used to support the findings of this study are included within the article.

\section{Conflicts of Interest}

There are no conflicts of interest regarding the publication of this paper.

\section{Acknowledgments}

This work was supported by the Guangzhou Science and Technology Project under grant no. 201802020003 and Guangdong Science and Technology Project under grant no. 2016A010101024.

\section{References}

[1] S. S. Gao, Q. Luo, and F. Zhu, Circularly Polarized Antennas, John Wiley \& Sons, Hoboken, NJ, USA, 2013.

[2] C. M. Peng, I. Chen, C. C. Hung, and Z. Hao, "Dual crossshaped shorted-slots loaded patch antenna for WLAN applications," International Journal of Applied Electromagnetics and Mechanics, vol. 50, no. 2, pp. 225-232, 2016.

[3] C. Wang, M. Shih, and L. Chen, "A wideband open-slot antenna with dual-band circular polarization," IEEE Antennas and Wireless Propagation Letters, vol. 14, pp. 1306-1309, 2015.

[4] S. Mener, R. Gillard, and L. Roy, "A dual-band dual-circularpolarization antenna for Ka-band satellite communications," IEEE Antennas and Wireless Propagation Letters, vol. 16, pp. 274-277, 2017.

[5] Y. Sung, "Dual-band circularly polarized pentagonal slot antenna," IEEE Antennas and Wireless Propagation Letters, vol. 10, pp. 259-261, 2011.

[6] Nasimuddin, Z. N. Chen, and X. Qing, "Dual-band circularly polarized \$S\$-shaped slotted patch antenna with a small frequency-ratio," IEEE Transactions on Antennas and Propagation, vol. 58, no. 6, pp. 2112-2115, 2010. 
[7] S. Lee, S. Pyo, and J. H. Kim, "Dual-band bidirectional circularly polarized microstrip antenna for CubeSat system," Microwave and Optical Technology Letters, vol. 60, no. 12, pp. 2989-2992, 2018.

[8] X. Sun, Z. Zhang, and Z. Feng, "Dual-band circularly polarized stacked annular-ring patch antenna for GPS application," IEEE Antennas and Wireless Propagation Letters, vol. 10, pp. 49-52, 2011.

[9] C.-M. Su and K.-L. Wong, "A dual-band GPS microstrip antenna," Microwave and Optical Technology Letters, vol. 33, no. 4, pp. 238-240, 2002.

[10] M. Hyeon, Y. Sung, and E. Kim, "Dual-band circular polarised square-ring patch antenna loaded lumped capacitors," IET Microwaves, Antennas \& Propagation, vol. 12, no. 15, pp. 2326-2331, 2018.

[11] Y. Sung, "Dual-band circularly polarized stack-ring antenna," Journal of Electromagnetic Engineering and Science, vol. 19, no. 1, pp. 37-41, 2019.

[12] S. Zuo, L. Yang, and Z. Zhang, "Dual-band CP antenna with a dual-ring cavity for enhanced beamwidth," IEEE Antennas and Wireless Propagation Letters, vol. 14, pp. 867-870, 2015.

[13] Y.-M. Cai, K. Li, Y.-Z. Yin, and X. Ren, "Dual-band circularly polarized antenna combining slot and microstrip modes for GPS with HIS ground plane," IEEE Antennas and Wireless Propagation Letters, vol. 14, pp. 1129-1132, 2015.

[14] Z.-X. Liang, D.-C. Yang, X.-C. Wei, and E.-P. Li, "Dual-band dual circularly polarized microstrip antenna with two eccentric rings and an arc-shaped conducting strip," IEEE Antennas and Wireless Propagation Letters, vol. 15, pp. 834837, 2016.

[15] G. Mayhew-Ridgers, J. W. Odendaal, and J. Joubert, "Singlelayer capacitive feed for wideband probe-fed microstrip antenna elements," IEEE Transactions on Antennas and Propagation, vol. 51, no. 6, pp. 1405-1407, 2003.

[16] Y.-F. Lin, H.-M. Chen, and S.-C. Lin, "A new coupling mechanism for circularly polarized annular-ring patch antenna," IEEE Transactions on Antennas and Propagation, vol. 56, no. 1, pp. 11-16, 2008.

[17] K.-L. Wong and T.-W. Chiou, "Broad-band single-patch circularly polarized microstrip antenna with dual capacitively coupled feeds," IEEE Transactions on Antennas and Propagation, vol. 49, no. 1, pp. 41-44, 2001.

[18] K.-L. Wong and T.-W. Chiou, "Broadband dual-polarized patch antennas fed by capacitively coupled feed and slotcoupled feed," IEEE Transactions on Antennas and Propagation, vol. 50, no. 3, pp. 346-351, 2002.

[19] H.-M. Chen and K.-L. Wong, "On the circular polarization operation of annular-ring microstrip antennas," IEEE Transactions on Antennas and Propagation, vol. 47, no. 8, pp. 1289-1292, 1999.

[20] H. Liu, C. Xun, S. Fang, and Z. Wang, "Beamwidth-enhanced low-profile dual-band circular polarized patch antenna for CNSS applications," International Journal of Antennas and Propagation, vol. 2019, Article ID 7630815, 13 pages, 2019.

[21] M. Chen and C.-C. Chen, "A compact dual-band GPS antenna design," IEEE Antennas and Wireless Propagation Letters, vol. 12, pp. 245-248, 2013.

[22] S. Gupta and G. Mumcu, "Dual-band miniature coupled double loop GPS antenna loaded with lumped capacitors and inductive pins," IEEE Transactions on Antennas and Propagation, vol. 61, no. 6, pp. 2904-2910, 2013. 


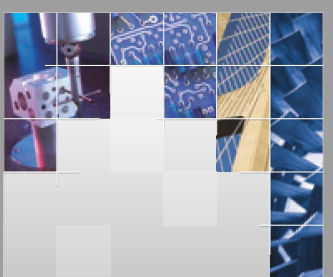

\section{Enfincering}
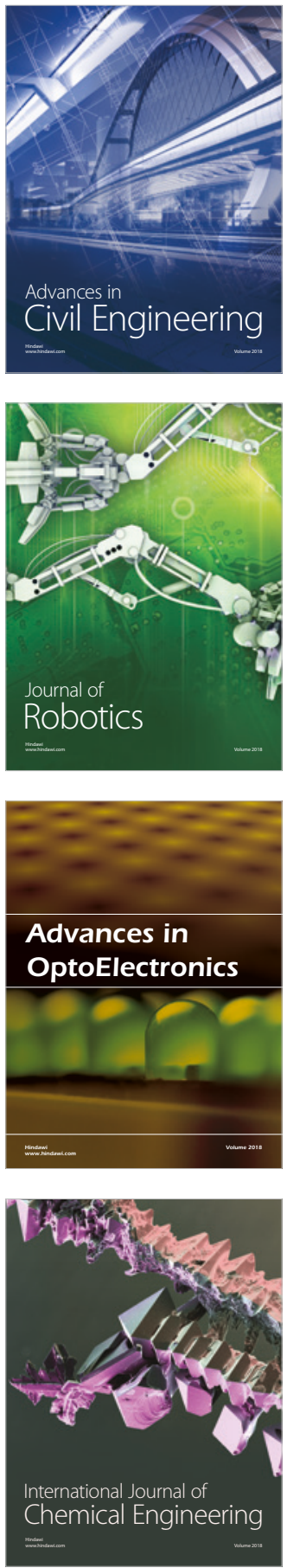

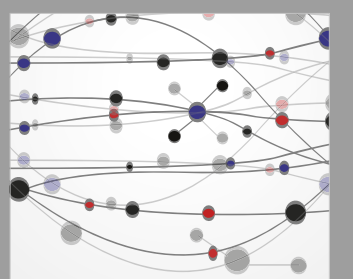

\section{Rotating \\ Machinery}

The Scientific World Journal

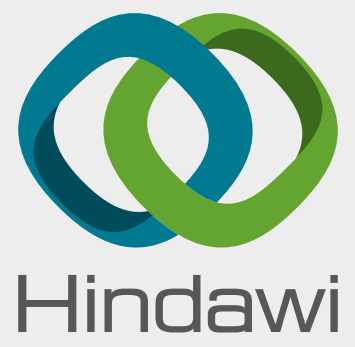

Submit your manuscripts at

www.hindawi.com
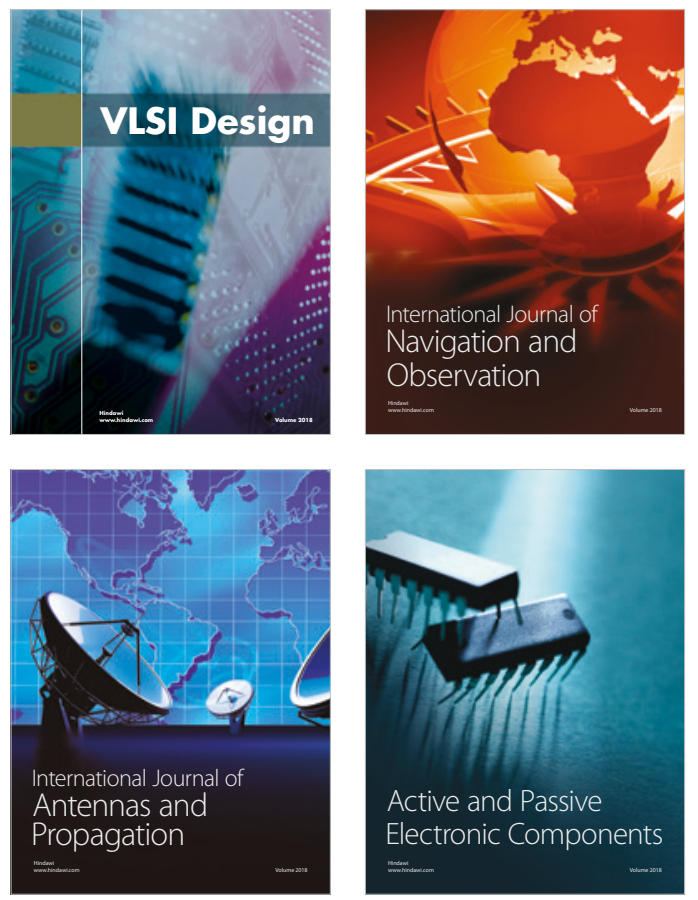
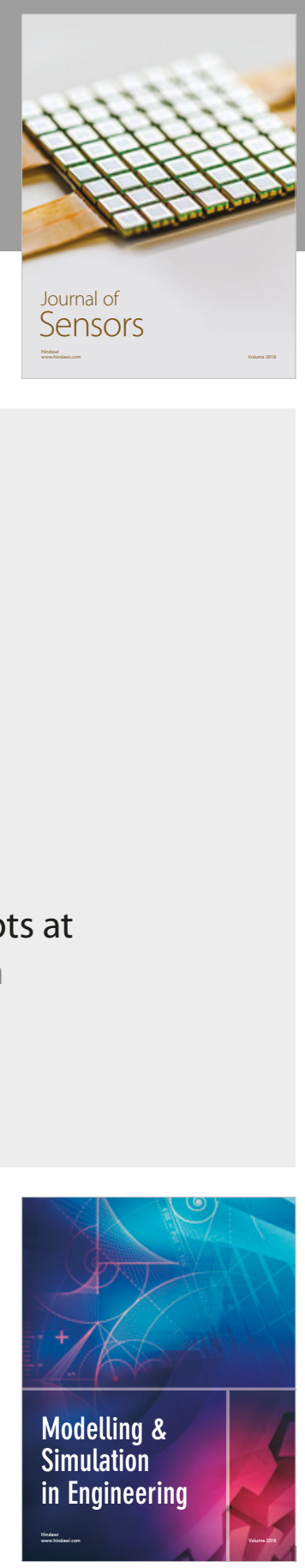

\section{Advances \\ Multimedia}
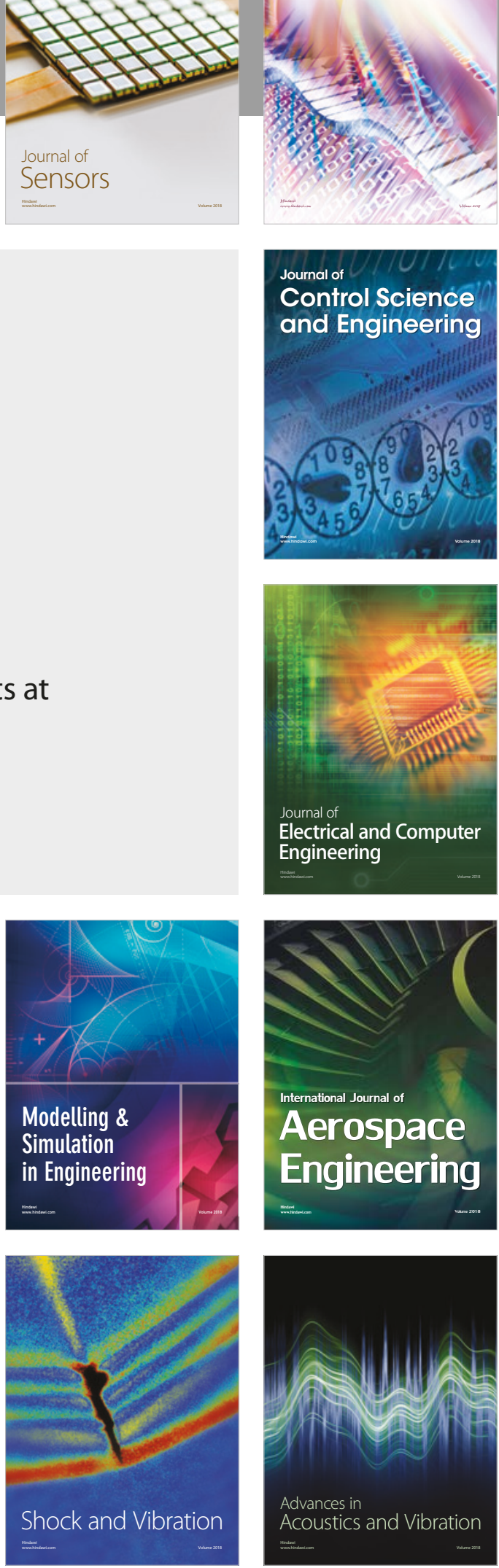